\title{
CRIAÇÃO LITERÁRIA - UM ENSAIO PARA ESCRITOR
}

Maria Cristina Ribas*

"Uma parte de mim/é todo mundo: / outra parte é ninguém:/ fundo sem fundo./.../Uma parte de mim é só vertigem:/ outra parte, linguagem./Traduzir uma parte/ na outra parte' -que é uma questão/ de vida ou morte -/ será arte?"

Ferreira Gullar'

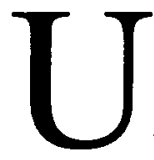

m dos maiores e mais instigantes desafios com que tenho me defrontado na vida acadêmica, vale ressaltar, em uma das tarefas que considero vitais à humanidade, a docência, é desenvolver o exercício da Criação Literária. As considerações a seguir advêm de um trabalho minucioso com o estudo e a prática individual na Literatura, com a imersão em Cursos e Oficinas desenvolvidas na Pontifícia Universidade Católica do Rio de Janeiro, junto às mais diversas faixas etárias.

* Pontifícia Universidade Católica do Rio de Janeiro.

1 Fragmento do poema "Traduzir-se", de Ferreira Gullar.(1a.,6a. e 7a. estrofes).1980, 439. 
Espaço interdisciplinar por excelência, ponto de fuga em que se tocam ansiedades humanas em princípio paradoxais, tais como fluidez e permanência, retraimento e exposição, orgulho e baixo estima, obrigação e necessidade - pares tantas vezes amalgamados por uma cadeia de enganos -, o ato de "criar" transita por modelos arquetípicos, imitaçōes infundadas, inspirações e transpirações vitais, enfim, projeções que variam do lúdico, passando pelo terapêutico, até a busca e o domínio de técnicas "novas". Mas o que a experiência tem me mostrado é que o objetivo mais explícito daqueles que procuram uma Oficina ou Curso de Criação Literária é o estímulo para escrever e um olhar que lhe pontualize se "aquilo" que produziu até então é "literatura." As hesitações, portanto, que trazem candidatos a uma Oficina desta natureza, demonstra que a maioria vem em busca de um apoio, testemunho e uma espécie de garantia para a sua própria prática de produção textual. Nesta perspectiva, geralmente o grupo esbanja sensibilidade, curiosidade, defesa e até mesmo uma certa desconfiança - até que seja provado o contrário, ou melhor, até que os sucessivos encontros provem a inutilidade deste temor.

Se é então extremamente delicado transitar por área tão fluida do ponto de vista daquele que se identifica como "criador", pensemos juntos na condição de quem, mesmo momentaneamente, pretende assumir a tarefa de levar outros a exercerem e exercitarem a criação, a se outorgarem o poder da linguagem , da materialização dos próprios e alheios pensamentos. Estimular a criação é também criar - uma via de mão dupla. Lembremos Clarice:

Adestrei-me desde os sete anos de idade para que um dia tivesse a língua em meu poder. E no entanto cada vez que eu vou escrever, é como se fosse a primeira vez.. Cada livro meu é uma estréia penosa e feliz. Essa capacidade de me renovar toda à medida que o tempo passa é o que eu chamo de viver e escrever." ${ }^{2}$

A aliança da escrita à vida assumida por Clarice Lispector fala, dentre outras grandezas, da experiência como fator vital no exercício da escrita. Criar ação. Não existe um manual ordenado logicamente para adestrar o candidato a romancista, ou poeta, ou contista. E quando afirmo a não existência de manual, refiro-me à total inadequação de tal guia-acessível-para-se-chegar-a-lugar-nenhum em se tratando, basicamente, da produção literária. Com todas as ambigüidades que a prática provoca, com toda a singularidade que cada sujeito constitui, com toda a insatisfação e alegria que o resultado pode - ou não - trazer ao seu "dono", o grande

2 "As três experiências", Clarice Lispector. In: A descoberta do mundo. 
desafio é orientar sem formatar, levar ao aprimoramento sem castrar, estimular sem mentir. Especialmente porque, ao relacionar-se mais profundamente consigo mesmo, ao garimpar as mazelas do seu texto, ao encontrar o ouro, separar o joio do trigo e às vezes optar pelo joio, o autor recém-nascido é obrigado a enfrentar o mundo, a diluir parte do seu eu, abrir-se à projeção alheia. A partir daí vai contracenar com o outro na virtualidade do texto literário.

O terreno é movediço, apoia e atraiçoa e, sabemos, a percepção desta duplicidade já deveria ser questão de senso comum, principalmente por ter sido levada a público diversas vezes. A esse respeito, a denúncia mais emblemática talvez seja a de Baudelaire em pleno séc XIX, quando declara frontalmente em versos, Hypocrite lecteur - mon sembable, - mon frère. ${ }^{3}$ Mas muitas das belas reflexões dos literatos infelizmente não chegam ao conhecimento da maioria. Tal especificidade se restringe aos estudiosos do tema. Daí a importância do docente estar sempre atento e disposto a atualizar o déjà $v u$, a reabastecer ou desconsiderar o clichê e a trazer ou atrasar o novo - atitude respaldada pela lição (?) dadaísta de considerar não só a carga de excludência do "ou", mas também a fértil noção de simultaneidade mais típica das conjunções aditivas.

Quando Ezra Poud escreve o seu abc da literatura explicando "How to study poetry" and "Warning", seu objetivo é formalizar um método - comparativo - para aqueles que, analogamente a um biólogo, de fato queiram atingir um mais alto grau de conhecimento na matéria literária. Sua pretensão é clara: "The book is not adressed to those who have arrived at full knowledge of the subject without knowing the facts." Obviamente será ele quem vai apresentar a matéria-prima necessária àquele que deseja tornar-se um expert em literatura. Interessa-nos aqui compreender que a comparação elogiada por Pound pressupõe um conhecimento prévio dos escritores mais representativos da literatura, os quais, no seu entendimento, são aqueles que mantêm a linguagem "eficiente", isto é, a sua precisão e a sua clareza. É o paideuma poundiano. Ou seja: "A ordenação do conhecimento de modo que próximo homem (ou geração) possa achar, o mais rapidamente possivel, a parte viva dele, e gastar um mínimo de tempo com itens obsoletos." " Para tal ele propõe um mini-antologia que vai de Homero a Rimbaud, passando por Shakespeare e John Donne. Vale considerar a relevância que Pound atribui ao acervo literário da humanidade como um patrimônio que não deve ser ignorado, mas conhecido e organizado de maneira que os demais possam ir além do que já foi de fato trilhado pelos antepassados. A escolha dos componentes deste paideuma seriam aqueles que fazem "grande literatura".

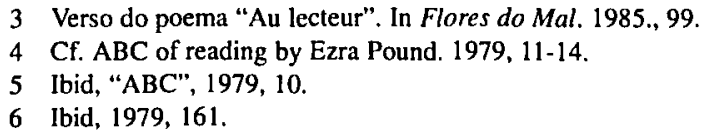


E adiante completa a reflexão, afirmando que "grande literatura é simplesmente linguagem carregada de significado até o máximo grau possível."7 Daí retira a noção de condensação, a partir do verbo alemão dichten, que corresponde ao substantivo Dichtung, que significa "poesia" e chega ao italiano condensare. A noção de condensação da poesia independe da extensão física do texto mas atrelase à sua suficiência, dado que tem se configurado nos Cursos de Criação Literária uma chave preciosa para trabalhar a dúvida quanto ao tamanho ideal do texto. A indagação ultrapassa a mera questão formal, seja o número de versos e estrofes num poema, seja o de linhas e capítulos numa prosa. $O$ aluno desloca a sua atenção da extensão física do texto entendida de forma isolada para o grau de "condensação" da linguagem e passa, então, a investigar a suficiência das palavras, a consistência das imagens, a suficiência da composição textual. E com esta prática individual, tem chegado a bons resultados, de maneira mais consciente e autônoma.

Quanto à questão da valorização da produção literária da humanidade, é um tópico cada vez mais delicado na contemporaneidade, que, sob a égide do imediatismo e do descartável, submetida à aceleração crescente, tende ao desconhecimento do antecedente, ao culto exacerbado à originalidade - o que sem parâmetro é inviável - e ao desinteresse pelo que não lhe diz respeito diretamente. Provavelmente Pound anteviu esta atitude e tentou, ainda que autoritariamente, prover esta carência fundamental. Em 1963, Eliot reiterava o mesmo ponto de maneira enfática, dizendo que

\footnotetext{
"Nenhum poeta, nenhum artista tem sua significação completa sozinho. Seu significado e a apreciação que dele fazemos constituem a apreciação de sua relação com s poetas e os artistas mortos. Não se pode estimá-lo em si: é preciso situá-lo, para contraste e comparação, entre os mortos." 8
}

Vale lembrar que a noção de "tradição" em T.S. Eliot não se refere apenas ao histórico, mas também ao fator estético; em outras palavras, não implica unicamente em revalorizar o passado, mas na receptividade do sujeito com relação a uma nova obra que ajuda a reavaliar a tradição, sendo logo absorvido por ela. Para o crítico a tradição engloba a manifestação individual. Tal postura é relida ao contrário por Harold Bloom,'9 que a desmistifica ao defender uma outra leitura dos pa-

7 Ibid, 1979, 40.

8 "Tradição e talento individual". 1989.

9 A anguistia da influência. 1991, 17. 
RIBAS, M. C. Criação Literária...

drões de apropriação e desapropriação (misprision) entre manifestações literárias de épocas distintas.

“...o poema é um 'ato de leitura', não um objeto, mas um movimento e uma postura em relação a um poema ou poemas anteriores, então a crítica é poesia em prosa, assim como a poesia é, ela mesma, uma forma de crítica." 10

Bloom amplia o ponto de vista ao mesmo tempo que o viabiliza no contexto contemporâneo. A relação deixa de ser apenas entre poetas, para sê-lo entre texto e leitor. Propõe a "desleitura" (misreading), a descontinuidade no jogo com os predecessores , chegando à apropriação do poeta mais velho, o retorno do precursor como se ele fosse novo; dito de outra forma, uma leitura às avessas do complexo de Édipo, "buscando acabar com a idealização de nossas versões oficiais de como um poeta [antigo] ajuda a formar outro." 11

E é uma das questões que subliminarmente emerge no trato com os estudantes em geral, sobretudo em se tratando de Literatura e Criação Literária. É possível, então, constituir novos paradigmas sem conhecer os predecessores? Como instituir desvios sem o conhecimento de modelos outros? É preciso negar os predecessores com a mesma ênfase com que já foram copiados, imitados? Sobre esta inquietude, Bloom sinaliza:

Édipo, cego, estava a caminho da divindade de oráculo, e os poetas fortes vêm seguindo na mesma trilha ao transformar sua cegueira face aos precursores em percepções revisionárias em suas próprias obras. ${ }^{12}$

Para que não seja repetida a cegueira edipiana, é fundamental que o filho seja forte o suficiente para afirmar-se diante do pai como força análoga em relação de descontinuidade, o que configura uma proposta de revisão do cânone literário entendido como "a relação de um leitor e escritor individuais com o que preservou do que se escreveu". ${ }^{13}$ Na dinâmica da Criação a releitura é mais um indicador da

10 Ibid, $1989,17$.

$111989,33$.

$121989,39$.

13 Id. "Uma elegia para o cánone". 1995, 25. 
necessidade do trabalho de indagação sobre o processo criativo e da premência da transpiração sobre o texto literário. Como construir um poema - ou prosa - com força para existir autonomamente? O que é um texto forte? Condensado? Uma linguagem consistente? Existe talento? Qual o conceito de Tradição?

Esta cadeia de questões deve fazer parte do exercício de produção de textos literários. Ainda mais considerando o dado de que a leitura de textos canônicos torna-se progressivamente menor devido às condições históricas e psicológicas do homem contemporâneo. Seus condicionamentos, seus parâmetros enfatizam outros aspectos e consolidam a cultura por outras vias, não necessariamente a livresca, não da mesma forma e nem com a mesma intensidade.

Apesar da consciência com relação a este "novo" perfil, volta e meia é comum manifestarmos preocupação com a falta de leitura, com o desconhecimento da maioria sobre os clássicos da literatura. Mas será de fato útil perguntar se ainda ouviremos declarações de amor aos livros como referenciais absolutos de uma existência?

Sartre, certa vez, ao refletir sobre a sua vida, declarou: "Comecei minha vida como hei de acabá-la, sem dúvida: no meio dos livros." ${ }^{4}$ Hoje, dificilmente esta absolutização é um fenômeno recorrente. Entretanto, o cenário está em plena mudança e longe de ser minha tendência prostrar-me ante um saudosismo nostálgico do que não vivi, pensamento que mais paraliza do que faz atuar no mundo circundante. Quando o filósofo relembra a infância, é possível perceber a visceralidade dos livros na sua formação:

Nunca esgaravatei a terra nem farejei ninhos, não herborizei nem joguei pedras nos passarinhos. Mas os livros foram meus passarinhos e meus ninhos, meus animais domésticos, meu estábulo e meu campo; a biblioteca era o mundo colhido num espelho; tinha a sua espessura infinita, a sua variedade e a sua imprevisibilidade. Eu me lançava a incríveis aventuras: era preciso escalar as cadeiras, as mesas, com o risco de provocar avalanches que me teriam sepultado. ${ }^{15}$

Hoje as aventuras são outras. Não se reconhece com freqüência a aventura livresca de Sartre, Machado de Assis, Saramago, Clarice. Não daquela forma. A ansiedade por "Traduzir-se", entretanto, persiste. Insiste. Mas não da mesma for- 
ma. Por tudo isso faz-se mister que tais - e outras - indagações em cadeia devam ser sempre bem vindas e continuamente analisadas em seus mínimos detalhes. Urge aproveitar cada novo movimento que se instaura na dinâmica da leitura e produção textual. Numa orquestra, quem rege precisa ter o conhecimento da unidade e do todo. Identificar o som de cada instrumento, seu campo de atuação, variações e permanências, possibilidades combinatórias e incompatibilidades. Há que se avaliar o alcance de cada harmonia e ao mesmo tempo a acuidade auditiva do público; e ainda ter em si o espaço para a surpresa, para o "des-concerto", o ouvido sensivel a desafinações e dissonâncias que eventualmente possam emergir de uma... intenção . Ou seria descuido?

Neste momento é a intuição fina que compreende a diferença entre o propósito e o erro, a opção e o desconhecimento, dubiedades que tantas vezes emergem nas dinâmicas propostas ao grupo, agora voltando para as Oficinas de Criação Literária. É fundamental devolver a cada um dos componentes o espelho de sua própria atuação para que procedam à desautomatização da percepção ${ }^{16}$, desconheçam momentaneamente o objeto que produziram e o elevem à categoria de obra de arte - se descobrirem neste objeto consistência para tal. É preciso estimular a mudança do olhar, o descongelamento do ponto de vista ; favorecer o insight, o alumbramento de Manuel Bandeira, a epifania de Clarice, o ver com os olhos livres oswaldiano. Mas o processo de singularização vai depender da interação do autor com sua obra e desta com os demais colegas , caracterizados na oficina como um primeiro ensaio de público.

E mais uma vez, e a quase todo momento, novos obstáculos, melhor dizendo, desafios, outras modalidades de avalanches vão emergindo e sepultando pensamentos, recordações e experimentos no cenário reduzido e amplo da "Oficina" de "Criação Literária". A escrita não é a mesma mas a sua necessidade ainda grita por entre aqueles que a elegeram como forma de expressar-se, existir, viver. Enfim, traduzir-se.

\section{ABSTRACT}

This paper focuses on the act of literary creation conceived as a special way of producing fictional narrative and poems as conducted in creative writing workshops at the Catholic University of Rio de Janeiro (PUC-Rio). The methodology discussed here is a result of several years of intensive study and previous experience in the field whereby a series of theoretical and methodological issues were 
revised, especially the concepts of ego and alter and their extensions in fiction and confession, tradition and individual talent, inspiration and perspiration, writer and reader. An examination of several writers' views on creative writing including those of Ferreira Gullar, Charles Baudelaire, Clarice Lispector as well as a number of representative literary critics such as Ezra Pound, T. S. Eliot, Harold Bloom, Stanley Fish and Umberto Eco was helpful. As a result, the writing process is argued an act which demands constant attention and patience at a number of different levels on the part of the writer.

Key words: Maria Cristina Ribas, Creation, experience and literature.

\section{RESUMO}

Este trabalho focaliza o ato da criação literária concebido como um estilo especial de produção de narrativa ficcional e poema, em oficinas, na Universidade Católica do Rio de Janeiro (PUC-RJ). A metodologia discutida aqui é resultado de vários anos de estudo intenso e experiência prévia no campo, tendo em vista que uma série de aspectos teóricos e metodológicos devem ser revisados, especialmente os conceito de ego e alter e suas extensões em ficção e confissão, tradição e talento individual, inspiração e transpiração, autor e leitor. Procedeu-se ao exame de vários autores sob um ponto de vista de escrita criativa, tais como as de Ferreira Gular, Charles Baudelaire, Clarice Lispector, bem como um número representativo de críticos literários tais como Ezra Pound, T. S. Eliot, Harold Bloom, Stanley Fish e Umberto Eco como resultado, o processo de escrita é demonstrado como um ato que demanda atenção constante e paciência devido a um número de diferentes níveis experimentados pelo escritor.

Palavras-chaves: Maria Cristina Ribas, criação, experiência e literatura.

\section{REFERÊNCIAS}

BAUDELAIRE, Charles. As flores do mal. (trad. Ivan Junqueira). Rio de Janeiro: Nova Fronteira, 1985.

BLOOM, Harold. O cânone ocidental. Os livros e a escola do tempo. Rio de Janeiro: Objetiva, 1995.

A angústia da influência: uma teoria da poesia. Rio de Janeiro: Imago, 1991. 
ELIOT, T,S..Tradição e talento individual. São Paulo: Art Editora, 1989.

GULLART, Ferreira. Toda poesia.!950-1980. Rio de Janeiro: CivilizaçÃo Brasileira, 1980.

LISPECTOR, Clarice. A descoberta do mundo.

POUND, Ezra. $A B C$ of Reading. London: Faber \& Faber, 1970.

SARTRE, Jean-Paul. As palavras. São Paulo: Difusão européia do livro, 1964.

SCHNAIDERMAN, Boris. Teoria da literatura - formalistas russos. 2ed.. Porto Alegre: Globo, 1976. 